\title{
Changing patterns in long-acting bronchodilator trials in chronic obstructive pulmonary disease
}

This article was published in the following Dove Press journal:

International Journal of COPD

7 January 2011

Number of times this article has been viewed

\author{
James F Donohue' \\ Paul W Jones ${ }^{2}$ \\ 'Division of Pulmonary Disease \\ and Critical Care Medicine, School \\ of Medicine, University of North \\ Carolina at Chapel Hill, Chapel Hill, \\ NC, USA; '2 St. George's, University \\ of London, London, UK
}

\begin{abstract}
Chronic obstructive pulmonary disease (COPD) is a major cause of morbidity and mortality worldwide. Developments in the understanding of COPD have led to standard guidelines for diagnosis, treatment, and spirometry assessments, which have in turn influenced trial designs and inclusion criteria. Substantial clinical evidence has been gained from clinical trials and supports a positive approach to COPD management. However, there appear to be changing trends in recent trials. Large bronchodilator studies have reported lower improvements in trough forced expiratory volume in 1 second $\left(\mathrm{FEV}_{1}\right)$ values versus placebo than were observed in earlier studies, while the rate of $\mathrm{FEV}_{1}$ decline seems to be lower in more recent trials. In addition, recent evidence has called into question the usefulness of bronchodilator reversibility testing as a trial inclusion criterion. Baseline patient populations and use of concomitant medications have also changed over recent years due to increased treatment options. The impact of these many variables on clinical trial results is explored, with a particular focus on changes in inclusion criteria and patient baseline demographics.
\end{abstract}

Keywords: chronic obstructive pulmonary disease, clinical trials, forced expiratory volume in 1 second, long-acting bronchodilators, lung function

\section{Introduction}

Chronic obstructive pulmonary disease (COPD) is a major public health concern and is currently the fourth leading cause of death in the United States. ${ }^{1}$ COPD is a smokingrelated lung disease that progresses over several years with increasing respiratory symptoms (eg, dyspnea, coughing, and sputum production) and systemic effects (eg, weight loss, skeletal muscle dysfunction, and increased risk of cardiovascular disease). ${ }^{1}$

In previous decades, treatment options for COPD were limited. However, the past 10-15 years have seen a large increase in clinical trials examining different treatments for this disease and substantial developments in COPD management, for example, long-acting $\beta_{2}$-agonists, long-acting muscarinic antagonists, and their combination with inhaled corticosteroids (ICS). Bronchodilators are the mainstay of pharmacologic treatment of COPD, and the most widely used are $\beta_{2}$-agonists (eg, salbutamol, terbutaline, formoterol, and salmeterol), anticholinergics (eg, ipratropium and tiotropium), and methylxanthines (eg, theophylline). Bronchodilators in combination with each other and with ICS have also been investigated.

Understanding of the clinical phenotypes of COPD is evolving, and there is increasing clinical evidence to guide COPD management. However, several unanswered questions remain due to the variability in clinical trial procedures and patient populations. 
This review of trials of long-acting bronchodilators examines trends observed in recent COPD trials and explores the factors that may have impacted on the results, with a particular focus on changes in patients' lung function over time.

\section{Literature analysis}

A PubMed literature search (restricted to English literature; no date restriction) using the terms COPD (MeSH) and salmeterol or formoterol or tiotropium was carried out on May 14, 2009, and yielded 223 articles (search limits were: clinical trial, meta-analysis, randomized controlled trial, and humans). To minimize problems due to small sample sizes or short study durations, only full articles reporting randomized, placebo-controlled clinical trials of at least 500 patients and duration of at least 6 months were selected (18 articles) for detailed assessment.

\section{Recent trends in bronchodilator clinical trial results}

Forced expiratory volume in 1 second $\left(\mathrm{FEV}_{1}\right)$ is the principal measure of lung function used in the assessment of COPD. A minimum clinically important difference (MCID) has not been defined, although improvement of about 100-120 mL in trough $\mathrm{FEV}_{1}$ has been suggested as a possible benchmark for bronchodilators and anti-inflammatory agents, but this is not based on quantitative data. ${ }^{2,3}$ Regulators may consider a change in $\mathrm{FEV}_{1}$ of $5 \%-10 \%$ from baseline values to be clinically meaningful, and that a $<3 \%$ change from baseline is not clinically important. ${ }^{3}$ Assuming a baseline $\mathrm{FEV}_{1}$ of $1.1 \mathrm{~L}$, this would equate to an increase of $55-110 \mathrm{~mL}$, and not $<33 \mathrm{~mL}$. Further consideration of a clinically meaningful change is needed, particularly since recent results from large clinical studies evaluating a range of bronchodilators have reported lower improvements in trough $\mathrm{FEV}_{1}$ values for monotherapies than those reported in earlier studies.

For example, several studies have reported results of the long-acting anticholinergic, tiotropium. The recent 4-year Understanding Potential Long-term Impacts on Function with Tiotropium (UPLIFT) trial $(\mathrm{N}=5992)$ investigated tiotropium versus placebo in patients with COPD, and throughout the study, trough $\mathrm{FEV}_{1}$ was significantly improved versus placebo by $87-103 \mathrm{~mL}$ (Table 1). ${ }^{4}$ This contrasts with a number of previous studies that reported improvements in trough $\mathrm{FEV}_{1}$ values with tiotropium over placebo that ranged from 100 to $150 \mathrm{~mL}$ (Table 1 and Figure 1)..$^{5-11}$

The long-acting $\beta_{2}$-agonist, salmeterol, has demonstrated varying improvements in trough $\mathrm{FEV}_{1}$ compared with placebo of 59-92 mL (Table 1). ${ }^{67,12-14}$ A recent study of another longacting $\beta_{2}$-agonist, formoterol, showed improved trough $\mathrm{FEV}_{1}$ compared with placebo $(40 \mathrm{~mL})$, but most of the formoterol studies were not powered on trough $\mathrm{FEV}_{1}$ (Table 1). ${ }^{15}$ Since our literature search was carried out, a large, 12-month, randomized, double-blind study of 1964 patients has been reported, in which budesonide/formoterol demonstrated improvements in trough $\mathrm{FEV}_{1}$ compared with placebo $(\sim 100-110 \mathrm{~mL} ; P<0.001) .{ }^{16}$ Salmeterol in combination with the ICS, fluticasone, has demonstrated improvements in trough $\mathrm{FEV}_{1}$ compared with placebo ranging from 132 to $161 \mathrm{~mL},{ }^{12-14}$ and the combination of formoterol and budesonide improved trough $\mathrm{FEV}_{1}$ compared with placebo by a range of $50-80 \mathrm{~mL}$ (Table 1 ). ${ }^{15}$ Short-acting $\beta_{2}$-agonists (eg, salbutamol) and anticholinergics (eg, ipratropium) have a 4-6 h duration of action and, therefore, have a lower effect on trough $\mathrm{FEV}_{1}$ compared with longer-acting agents and were not included in the literature search. ${ }^{17}$

A new long-acting antimuscarinic agent, aclidinium bromide, is also under development and two large, 12-month, randomized, double-blind studies of 1647 patients in total have been reported since our literature search was carried out. ${ }^{18,19}$ When given once daily, $200 \mu \mathrm{g}$ inhaled aclidinium bromide demonstrated improvements in trough $\mathrm{FEV}_{1}$ compared with placebo of 59-67 $\mathrm{mL}(P<0.001)$ at week 28 .

Variable results in peak (ie, postdose) $\mathrm{FEV}_{1}$ have also been observed for individual agents across different trials (Table 1). Peak $\mathrm{FEV}_{1}$ compared with placebo ranged from 28 to $191 \mathrm{~mL}^{6,12-14,20,21}$ for salmeterol monotherapy, $76-231 \mathrm{~mL}^{6,12-14,20}$ for salmeterol + fluticasone, $92-140 \mathrm{~mL}^{15,22}$ for formoterol, 160-170 $\mathrm{mL}^{15}$ for formoterol + budesonide, and 47-244 mL for tiotropium. ${ }^{4-6,8,23}$

There are no immediately identifiable reasons for the differences in measured effect size for the same agent in different studies. It may simply be due to random sampling from the worldwide population of COPD patients; however, it may be useful to explore other possible mechanisms, which are evaluated in this review.

\section{Observed changes to COPD clinical trial procedures, inclusion criteria, and baseline demographics Guidelines for COPD diagnosis and definition}

Concerted efforts to define COPD have led to the development of guidelines for diagnosis, such as the Global Initiative for Chronic Obstructive Lung Disease (GOLD) and 


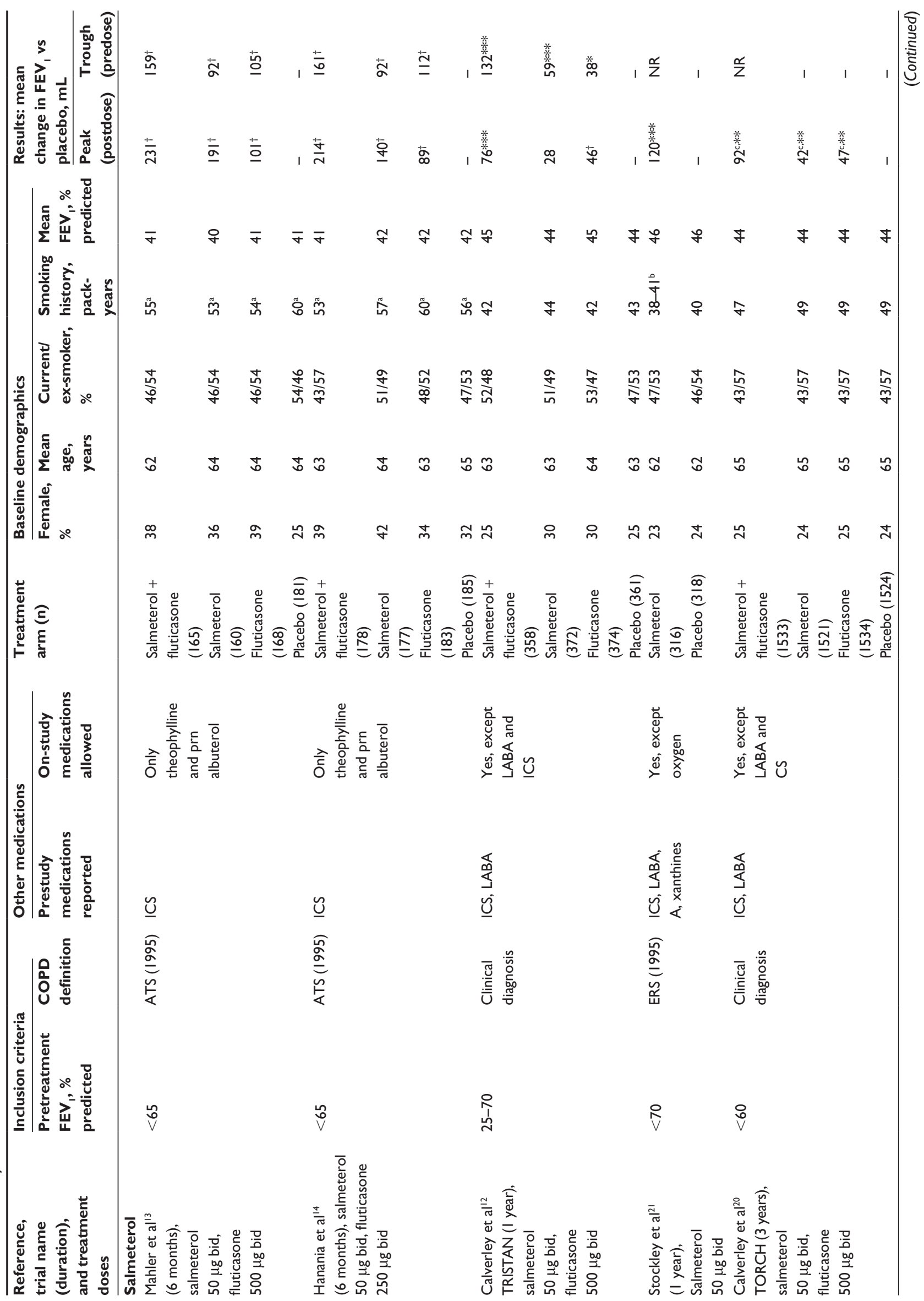




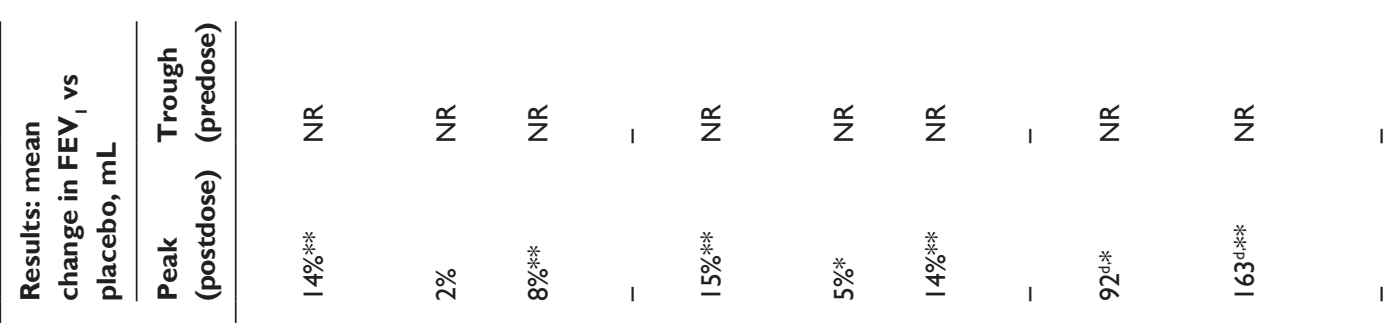

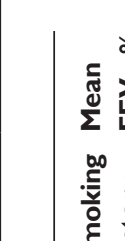

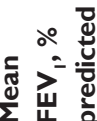

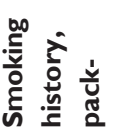

参

焉

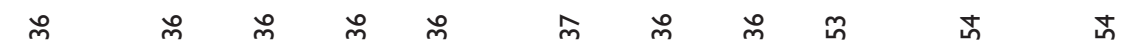

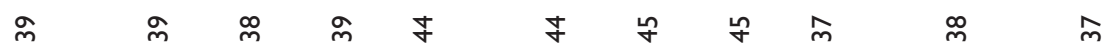

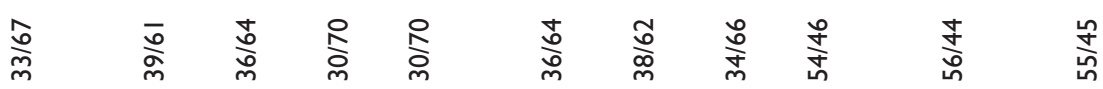

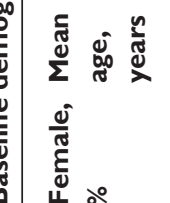

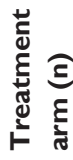

$\begin{array}{llllllllllll}2 & 2 & 0 & 0 & 7 & 7 & 0 & 0 & 8 & 8 & 8\end{array}$

ส

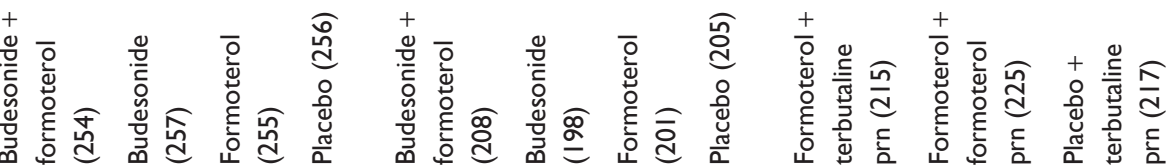

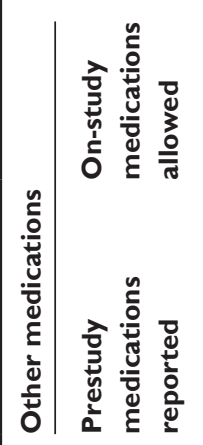

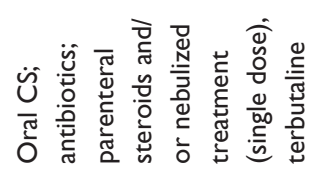

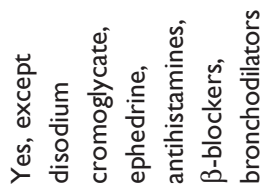

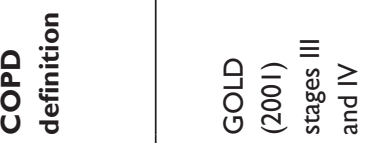

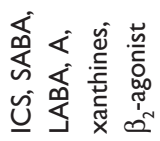

造

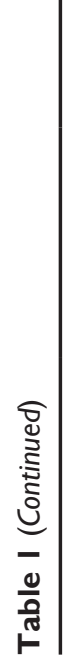

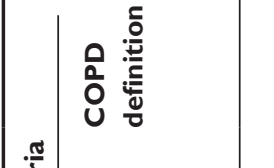

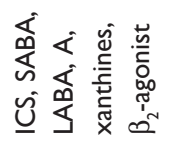

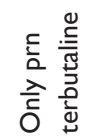

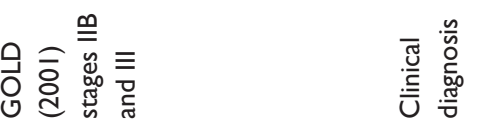

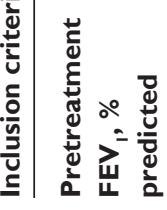

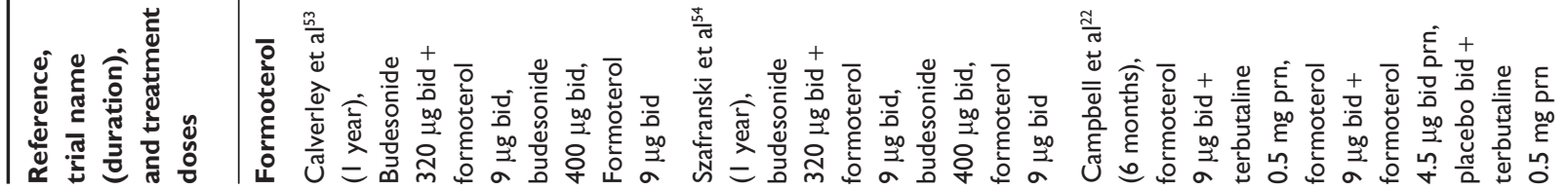




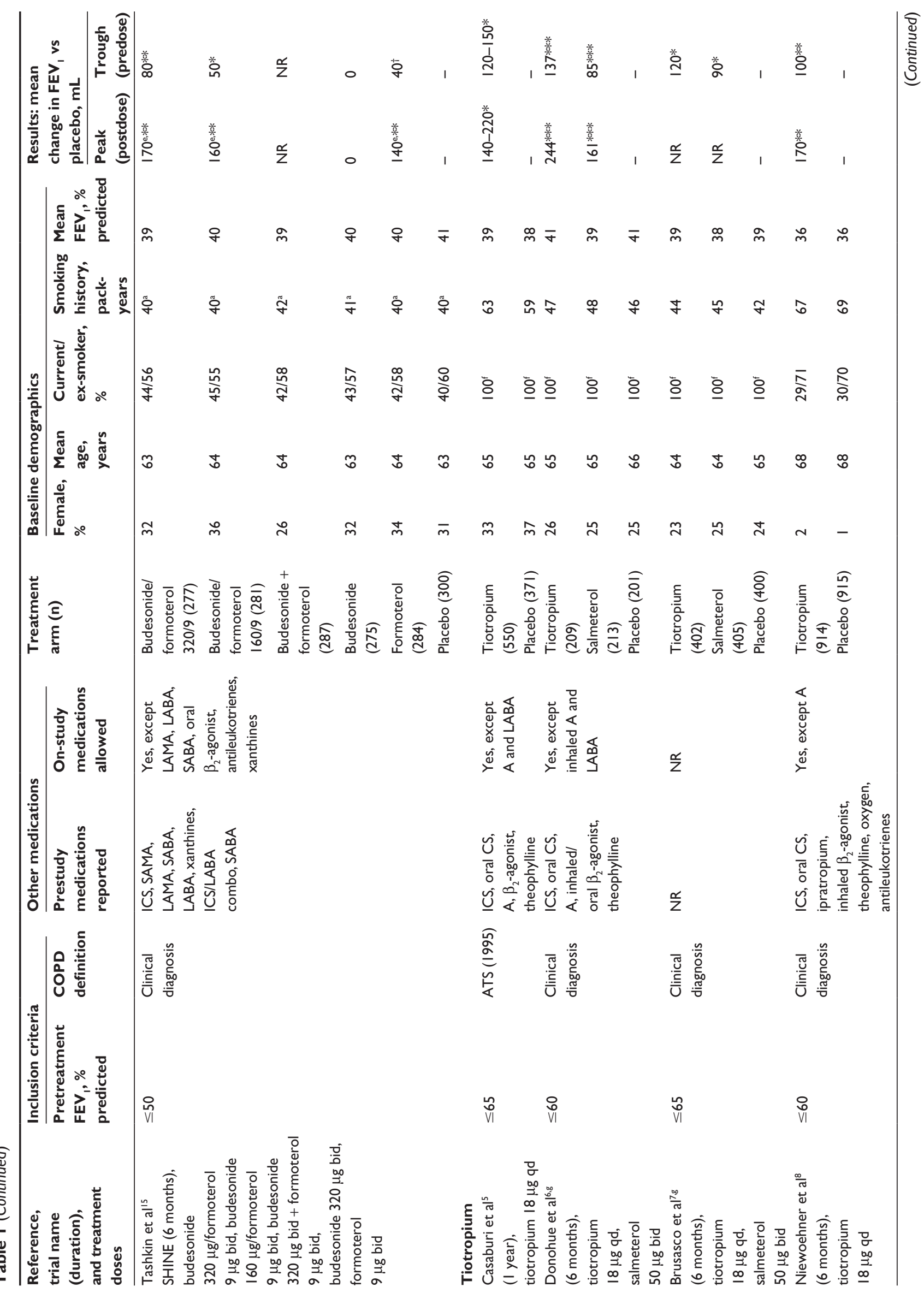




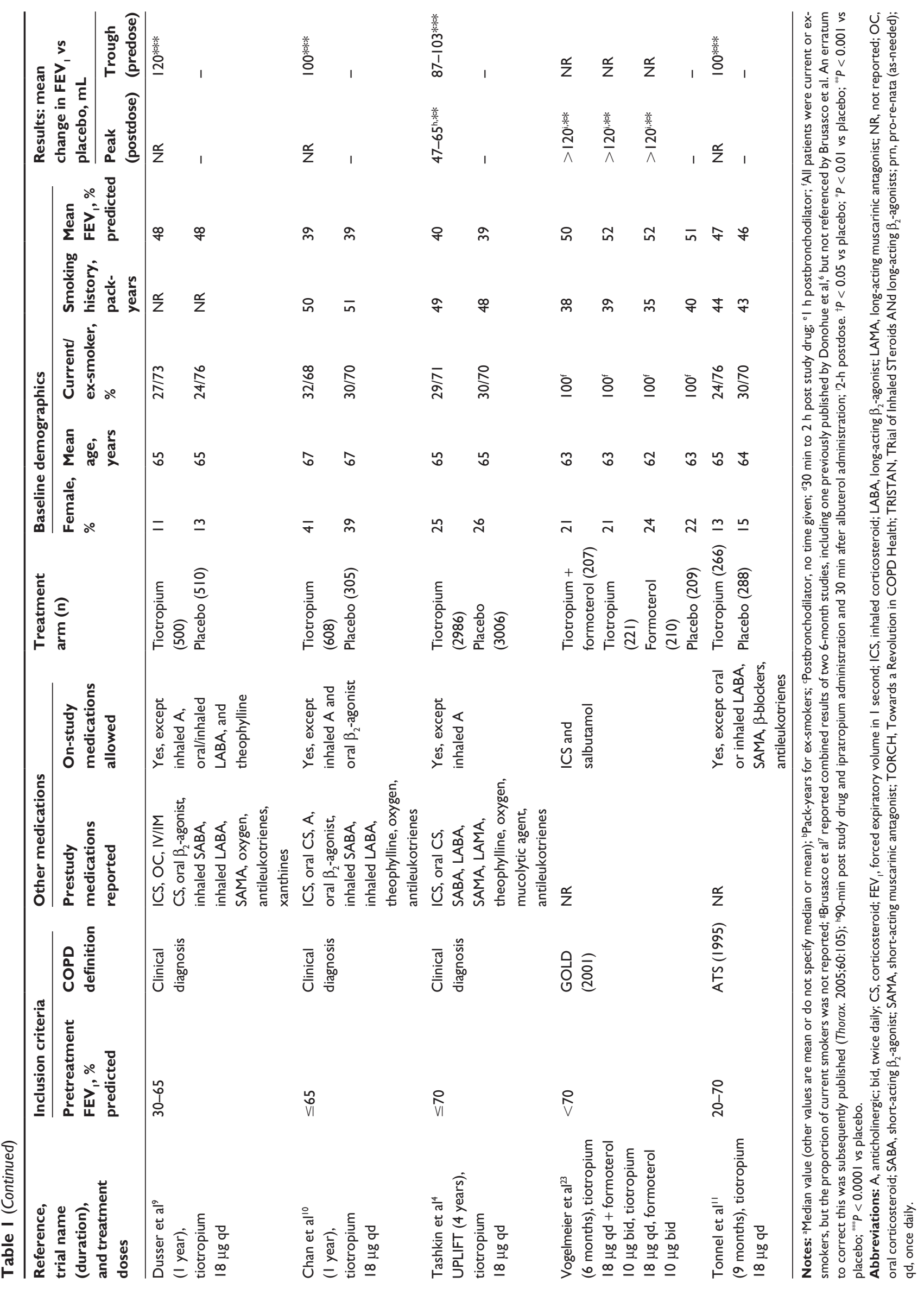




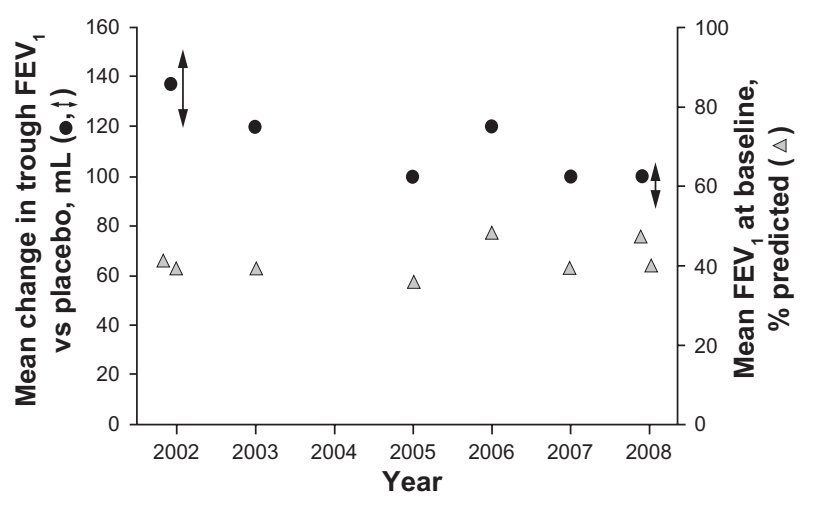

Figure I Treatment effect with tiotropium (left-hand axis) and baseline FEV, (righthand axis) against study publication date (Donohue et al, ${ }^{6}$ Casaburi et al (treatment effect results reported as a range), ${ }^{5}$ Brusasco et al, ${ }^{7}$ Niewoehner et al, ${ }^{8}$ Dusser et al, ${ }^{9}$ Chan et $\mathrm{al}^{10}{ }^{10}$ Tonnel et al, ${ }^{11}$ and Tashkin et $\mathrm{al}^{4}$ (treatment effect results reported as a range).

Abbreviation: $\mathrm{FEV}_{\text {, }}$, forced expiratory volume in I second.

American Thoracic Society (ATS)/European Respiratory Society (ERS) guidelines, which define COPD as a preventable and treatable disease characterized by airflow limitation that is not fully reversible. ${ }^{1,24}$ Compared with older definitions, ${ }^{25,26}$ this represents a paradigm shift toward positive thinking in COPD management. Changes in the understanding of the disease and evolving guidelines for its management will impact on clinical trial designs and procedures, and trial results, in turn, influence clinical guidelines.

\section{Lung function assessments}

Alongside guidelines for the diagnosis of COPD, the standardization of spirometry has also improved over recent years. Current spirometry guidelines were issued by the ATS/ERS in $2005,{ }^{27}$ which updated previous guidelines published in 1995 and 1987..$^{28,29}$ Recommendations specify acceptability and reproducibility criteria for forced vital capacity (FVC) and FEV assessments. A minimum of three acceptable assessments should have repeatability within $150 \mathrm{~mL}$ (or within $100 \mathrm{~mL}$ for those with an FVC $\leq 1.0 \mathrm{~L}),{ }^{27}$ which has shifted from the more lenient 1995 criteria of repeatability within $200 \mathrm{~mL} .{ }^{28}$ Once these criteria are met, ATS/ERS guidelines state that the largest FVC and $\mathrm{FEV}_{1}$ values should be selected, ${ }^{27}$ and although these are widely used, others recommend using mean values, such as the mean of the best three of five acceptable assessments. ${ }^{2}$

Spirometric tests performed in different clinics are often subject to variability due to technical and personal factors such as differences in the use and validation of equipment, as well as differences in measurement procedures, interpretation, and quality control., ${ }^{2,27}$ To help overcome such limitations, large trials such as UPLIFT have used centralized quality assurance of spirometry data.

\section{Effect of clinical trial on patient baseline demographics}

COPD is a heterogeneous disease, and differences in the patient inclusion criteria can substantially affect trial results and their translation into clinical practice guidelines.

Disease staging of COPD has been classified based on spirometry, ${ }^{1,24}$ and the relative proportions of patients with moderate, severe, and very severe COPD within trials may have an impact on results. For example, trough $\mathrm{FEV}_{1}$, the usual primary outcome measure in trials of long-term bronchodilators, is lower in patients with more severe disease and thus the magnitude of improvement in such patients would be expected to be lower. ${ }^{30}$ This has been shown in two studies of fluticasone propionate/salmeterol $(250 / 25 \mu \mathrm{g})$ in different patient populations. In a study of patients with COPD who had a mean baseline $\mathrm{FEV}_{1}$ of $42 \%$ predicted, fluticasone propionate/salmeterol increased trough $\mathrm{FEV}_{1}$ by $165 \mathrm{~mL}$ from baseline to end point, ${ }^{14}$ whereas in a second study of patients with more severe COPD (mean baseline $\mathrm{FEV}_{1}$ of $33 \%$ predicted), fluticasone propionate/salmeterol decreased trough $\mathrm{FEV}_{1}$ by $12 \mathrm{~mL}$ from baseline to end point. ${ }^{31}$ Subgroup analyses from the Towards a Revolution in COPD Health (TORCH) and UPLIFT trials have demonstrated improvements in lung function outcomes in patients with moderate (GOLD stage II) COPD. ${ }^{32,33}$ The TORCH analysis demonstrated improvements across different subgroups of GOLD stages, although lung function improvements decreased with increasing disease severity. ${ }^{33}$ Similar results have been observed in a subanalysis of the TRial of Inhaled STeroids ANd long-acting $\beta 2$ agonists (TRISTAN) study. ${ }^{34}$

Smoking is a key factor in COPD development and, until recently, smoking cessation was the only intervention that has been prospectively shown to slow the rate of lung function decline in COPD. ${ }^{35}$ The proportion of patients who are current smokers and patients' smoking history are, therefore, key baseline characteristics to consider. In a comparison of different trials, rates of $\mathrm{FEV}_{1}$ decline in different trials appear to be related to the proportion of current smokers at baseline (Figure 2). Indeed, a range of factors appears to influence FEV decline, including age, gender, and baseline $\mathrm{FEV}_{1}$, and could influence the rates observed in different studies. ${ }^{36}$ In the TORCH study, a slower rate of $\mathrm{FEV}_{1}$ decline in absolute milliliters per year was observed with patients $\geq 65$ years of age, with females, and those with a baseline $\mathrm{FEV}_{1}<30 \%$ predicted. ${ }^{36}$ However, when the rate of $\mathrm{FEV}_{1}$ decline was expressed as a percentage change per year, this relationship was preserved with patients $\geq 65$ years of age, but not with females and those with a baseline $\mathrm{FEV}_{1}<30 \%$ predicted. Moreover, a subanalysis 


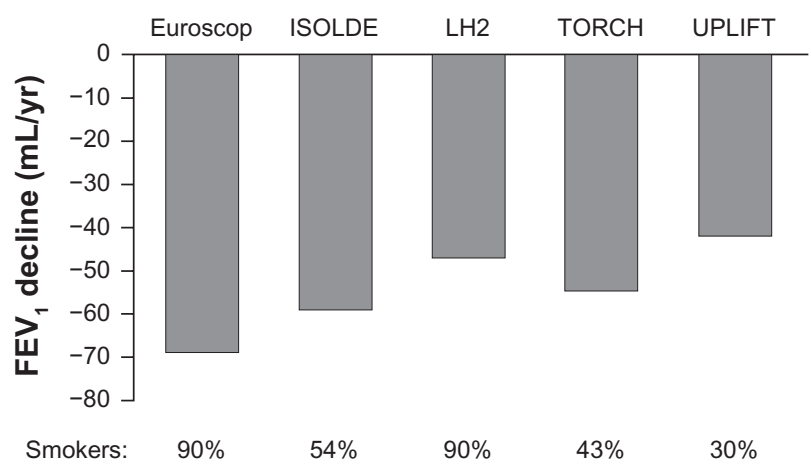

Figure 2 Rate of FEV decline in the placebo arm of long-term COPD studies. ${ }^{4,36,55-57}$ Abbreviations: COPD, chronic obstructive pulmonary disease; $\mathrm{FEV}_{1}$, forced expiratory volume in I second.

of TRISTAN study data reported that the improvements in trough $\mathrm{FEV}_{1}$ with salmeterol/fluticasone versus placebo were equivalent in women (by $152 \mathrm{~mL}$; 95\% confidence interval 95, 208) and men (by $127 \mathrm{~mL} ; 95 \%$ confidence interval 94, $159 ; P=0.455$ for the gender interaction). ${ }^{37} \mathrm{~A}$ recent analysis of the Framingham Offspring Cohort, which included 5124 male and female participants, showed that changes in lung function from adolescence to old age differ between healthy males and females. ${ }^{38}$ This analysis of the natural history of chronic airflow obstruction also confirmed the deleterious effects of smoking, as the rate of decline in $\mathrm{FEV}_{1}$ was increased in smokers compared with never-smokers. Quitting smoking earlier is better, as participants who quit after the age of 40 years showed no significant difference in $\mathrm{FEV}_{1}$ decline compared with continuous smokers.

\section{Effect of clinical trial dose selection}

There has also been a change in the focus of new drug applications to regulatory agencies, which may have affected outcomes of more recent studies compared with older studies. For example, the US Food and Drug Administration (FDA) routinely aims to identify the dose with the most favorable risk-benefit profile due to concerns about safety. This is, in part, a consequence of safety concerns about long-acting $\beta_{2}$-agonists in asthma: while there is a dose-response for $\mathrm{FEV}_{1}$ efficacy with formoterol, there is an escalating safety concern with higher doses. ${ }^{39}$ Recent pivotal Phase III studies have included lower doses along with the Phase IIa-identified dose; therefore, lower improvement in trough $\mathrm{FEV}_{1}$ and other end points may be seen compared with earlier studies. For example, Phase III trials of nebulized arformoterol investigated a $15 \mu \mathrm{g}$ twice-daily dose, as well as $25 \mu \mathrm{g}$ twice daily and $50 \mu \mathrm{g}$ daily. ${ }^{40,41}$ While the changes in trough or predose $\mathrm{FEV}_{1}$ were similar with the three doses, the mean percentage change in $\mathrm{FEV}_{1} \mathrm{AUC}_{(0-12)}$ was $12.7 \%, 13.9 \%$, and $18.9 \%$ with
$15 \mu \mathrm{g}$ twice daily, $25 \mu \mathrm{g}$ twice daily, and $50 \mu \mathrm{g}$ daily, respectively, compared with $2.7 \%$ with placebo and $9.8 \%$ with salmeterol. The lowest arformoterol dose (15 $\mathrm{g}$ twice daily) was chosen by FDA for license in the US. ${ }^{40}$

It has also been suggested that the rate of decline in lung function could be affected by bias from regression to the mean caused by missing data, such as in the TORCH study with salmeterol. ${ }^{42}$ This is due to the fact that no long-term COPD trials are designed to have a full intent-to-treat analysis of lung function decline. However, it has been argued that lung function decline is not influenced by regression to the mean in randomized, placebo-controlled trials such as TORCH, since any regression to the mean should affect all groups equally. ${ }^{43}$

\section{Concomitant medications}

Another recent key change in COPD trials inclusion criteria relates to concomitant medications, which are now in widespread use. In contrast to earlier studies when treatment options were limited, patients at baseline will now often already have received a variety of short- and long-acting bronchodilators and ICS. These will have already provided benefit to the patients, and their increased use over recent years will have shifted the baseline characteristics of patients entering trials. In the TORCH study, $8 \%-9 \%$ and $18 \%-22 \%$ of patients had received prior medication with an inhaled long-acting $\beta_{2}$-agonist and an ICS, respectively, and $27 \%-29 \%$ of patients had received a combination of the two. ${ }^{36}$ In the UPLIFT trial, $60 \%$ and $61 \%$ of patients were receiving prior medication with an inhaled long-acting $\beta_{2}$-agonist and an ICS, respectively. ${ }^{4}$

In many studies, however, patients are still required to stop the therapy they had been receiving during the run-in period prior to randomization, particularly if it is a member of the same class as the study medication. Withdrawal of maintenance treatment for COPD during a washout period may have two important effects. First, withdrawal of the drug may lead to worsening symptoms - so patients who do not meet stability criteria are not randomized to the study therapies. This would lead to selective exclusion of patients who may respond to the class of agents under test. Second, if the patients are randomized and receive placebo, there is evidence that those who have been withdrawn from either an ICS or a long-acting $\beta_{2}$-agonist during the run-in period are more likely to have an exacerbation during the trial. ${ }^{44}$

Concomitant medications are now excluded from use during the trial period less frequently than in the past, in part because of ethical issues; patients in both study drug and placebo arms are now likely to receive one or more respiratory medication other than the study drug. The UPLIFT study 
allowed all respiratory therapeutics, with the exception of another inhaled anticholinergic agent, in both the tiotropium and placebo arms. ${ }^{4}$ During the trial, $72 \%$ and $74 \%$ of patients reported having taken an inhaled long-acting $\beta_{2}$-agonist and an ICS, respectively, while $46 \%$ reported taking a fixed combination of the two. ${ }^{4}$ The study authors speculate that the concurrent medical care received during the study may have contributed to the generally lower rates of $\mathrm{FEV}_{1}$ decline across both the tiotropium and the placebo groups (which averaged $30 \mathrm{~mL} /$ year before bronchodilation and $41 \mathrm{~mL}$ after bronchodilation in the two groups). Post hoc analysis of a relatively small subgroup of patients in the UPLIFT trial who were not receiving maintenance therapy at baseline (13.5\% of the total population) suggests that there may be an influence of concomitant therapy on outcome. ${ }^{45}$ Another recent study has shown that there may be very clear benefits on $\mathrm{FEV}_{1}$ of adding different classes of agent together in COPD, since the addition of budesonide + formoterol to tiotropium showed a significant $(P<0.001)$ increase in predose (ie, trough $\mathrm{FEV}_{1}$ ) of $65 \mathrm{~mL}$ and postdose (peak) of $131 \mathrm{~mL}$ compared with tiotropium alone. ${ }^{46}$ It, therefore, remains a reasonable and testable hypothesis that there may be additive effects of pharmacological therapy on $\mathrm{FEV}_{1}$.

It is clear that prestudy and permitted concomitant therapies may have a significant impact on measured treatment effects due to selective recruitment, effects of concomitant therapy during the study, and events that occur during the trial, such as exacerbations.

\section{Bronchodilator reversibility}

Substantial progress in understanding the pathophysiology of COPD has been made in recent years. A key concern has been the differential diagnosis of COPD from chronic asthma. As asthma is associated with variable airway caliber, improvement in lung function (eg, $\mathrm{FEV}_{1}$ ) after bronchodilator treatment (termed bronchodilator reversibility) was proposed as a method of distinguishing between the two diseases. Bronchodilator reversibility for an individual patient is commonly defined as a postbronchodilator increase in $\mathrm{FEV}_{1} \geq 12 \%$ and $\geq 200 \mathrm{~mL}$ from baseline $\left(\mathrm{ATS}^{24}\right.$ and GOLD ${ }^{47}$ criteria) or as a $\geq 9 \%$ change in predicted $\mathrm{FEV}_{1}$ (ERS criteria $\left.^{48}\right){ }^{49}$ This approach has led to a common perception that COPD is irreversible, despite evidence that bronchodilator reversibility testing was not sensitive or specific enough to differentiate asthma from COPD using spirometry alone. ${ }^{50}$

Previously, European patients, and some patients in the US, were selected for COPD clinical studies based on a lack of bronchodilator reversibility by assessing how FEV, changed following a single dose of bronchodilator (acute changes). Clinical studies then investigated reversibility as the primary efficacy end point, in terms of changes in prebronchodilator $\mathrm{FEV}_{1}$ over time (chronic changes). Therefore, it is perhaps unsurprising that studies show a small response in terms of $\mathrm{FEV}_{1}$ change. ${ }^{51}$ Inclusion based on a lack of bronchodilator reversibility may act as a self-fulfilling prophecy for the trial outcomes.

In two studies that investigated salmeterol and fluticasone propionate, each as monotherapy and also in combination, patient randomization was stratified by reversibility to albuterol and investigative site. The results showed that, in both studies, patients with reversibility $\left(>12 \%\right.$ predicted $\left.\mathrm{FEV}_{1}\right)$ had a greater response to therapy than patients with nonreversibility (with $<4 \%$ predicted $\mathrm{FEV}_{1}$ ) (Figure 3). ${ }^{13,14}$ Another recent study in patients with reversibility and nonreversibility has shown that although both groups showed improved lung function with fluticasone propionate/salmeterol, the response was greater with patients with reversibility. ${ }^{52}$ Patients with a history of asthma (including childhood asthma) were excluded, and inclusion criteria required diagnosis of COPD with smoking history $\geq 10$ pack years, significant airway obstruction, and medication use indicative of COPD. Thus, the authors concluded that the greater responsiveness for patients with reversibility could be attributed to greater bronchodilator reversibility of their COPD and not asthma. The current evidence suggests that strict inclusion criteria based on bronchodilator reversibility are not necessary for future trials. Instead, patients with asthma could be differentiated from those with COPD on the basis of history (eg, nonsmoking) and normalization of lung function values.

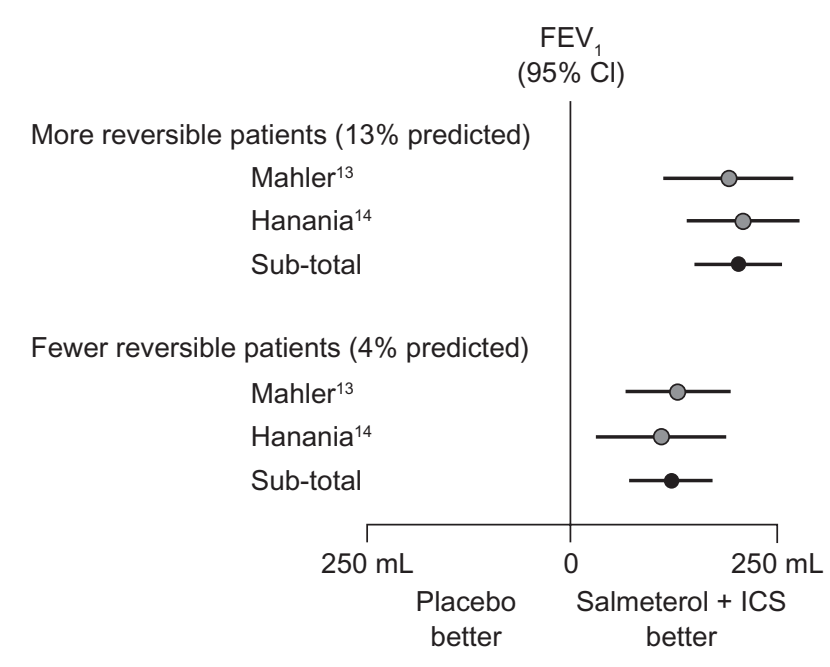

Figure 3 Response to inhaled corticosteroid (fluticasone propionate) + long-acting $\beta_{2}$-agonist (salmeterol) in reversible and nonreversible patients in COPD. . $3,14^{2}$ Abbreviations: $\mathrm{Cl}$, confidence interval; COPD, chronic obstructive pulmonary disease; $\mathrm{FEV}_{\mathrm{I}}$, forced expiratory volume in I second; ICS, inhaled corticosteroid. 


\section{Conclusions}

Significant advances in the understanding of COPD and increases in available treatment options have been made in recent years. Clinical evidence supports a positive approach to COPD management, and concerted efforts have produced standard guidelines for diagnosis and assessment. These guidelines influence clinical trial designs and protocols, the results of which feed back into clinical guidelines in a continuous process. This review of data from recent trials in COPD has some unexpected results, for example, the results from the recent large UPLIFT trial of tiotropium reported lower trough $\mathrm{FEV}_{1}$ outcomes than most previous studies with this drug. Current clinical trial results may not be directly comparable to earlier studies due to substantial changes in the availability of concomitant medications and in the baseline patient populations over time, including use of prior medications, smoking status and history, and disease severity. The impact of such factors on trial outcomes should be carefully evaluated, and consideration should be given as to whether long-acting bronchodilators can achieve a trough $\mathrm{FEV}_{1}$, value $>60-100 \mathrm{~mL}$ in future studies. This will require formal study with a full evaluation of indicative values for the MCID of trough and peak $\mathrm{FEV}_{1}$ changes.

\section{Acknowledgments}

We thank Emma Robinson from Complete Medical Communications who provided medical writing support funded by Almirall S.A., Barcelona, Spain. The views and opinions expressed herein are those of the authors.

\section{Disclosure}

JFD has served on advisory boards for Almirall and Forest Laboratories. PWJ has received fees from a number of pharmaceutical companies, including Almirall, for speaking at meetings and serving on advisory boards and has received support for research from GlaxoSmithKline.

\section{References}

1. Global Strategy for the Diagnosis, Management and Prevention of COPD. Global Initiative for Chronic Obstructive Lung Disease (GOLD). Updated 2009. Available from: http://www.goldcopd.com. Accessed 2010 Jan 13.

2. Donohue JF. Minimal clinically important differences in COPD lung function. COPD. 2005;2(1):111-124.

3. Cazzola M, MacNee W, Martinez FJ, et al. Outcomes for COPD pharmacological trials: from lung function to biomarkers. Eur Respir J. 2008;31(2):416-469.

4. Tashkin DP, Celli B, Senn S, et al. A 4-year trial of tiotropium in chronic obstructive pulmonary disease. N Engl J Med. 2008;359(15):1543-1554.

5. Casaburi R, Mahler DA, Jones PW, et al. A long-term evaluation of once-daily inhaled tiotropium in chronic obstructive pulmonary disease. Eur Respir J. 2002;19(2):217-224.
6. Donohue JF, van Noord JA, Bateman ED, et al. A 6-month, placebo-controlled study comparing lung function and health status changes in COPD patients treated with tiotropium or salmeterol. Chest. 2002;122(1):47-55.

7. Brusasco V, Hodder R, Miravitlles M, Korducki L, Towse L, Kesten S. Health outcomes following treatment for six months with once daily tiotropium compared with twice daily salmeterol in patients with COPD. Thorax. 2003;58(5):399-404. Erratum in Thorax. 2005;60(2):105.

8. Niewoehner DE, Rice K, Cote C, et al. Prevention of exacerbations of chronic obstructive pulmonary disease with tiotropium, a once-daily inhaled anticholinergic bronchodilator: a randomized trial. Ann Intern Med. 2005;143(5):317-326

9. Dusser D, Bravo ML, Iacono P. The effect of tiotropium on exacerbations and airflow in patients with COPD. Eur Respir J. 2006;27(3): 547-555.

10. Chan CK, Maltais F, Sigouin C, Haddon JM, Ford GT. A randomized controlled trial to assess the efficacy of tiotropium in Canadian patients with chronic obstructive pulmonary disease. Can Respir J. 2007;14(8): $465-472$.

11. Tonnel AB, Perez T, Grosbois JM, Verkindre C, Bravo ML, Brun M. Effect of tiotropium on health-related quality of life as a primary efficacy endpoint in COPD. Int J Chron Obstruct Pulmon Dis. 2008;3(2): 301-310.

12. Calverley PM, Pauwels R, Vestbo J, et al. Combined salmeterol and fluticasone in the treatment of chronic obstructive pulmonary disease: a randomised controlled trial. Lancet. 2003;361(9356):449-456.

13. Mahler DA, Wire P, Horstman D, et al. Effectiveness of fluticasone propionate and salmeterol combination delivered via the Diskus device in the treatment of chronic obstructive pulmonary disease. Am J Respir Crit Care Med. 2002;166(8):1084-1091.

14. Hanania NA, Darken P, Horstman D, et al. The efficacy and safety of fluticasone propionate (250 microg)/salmeterol (50 microg) combined in the Diskus inhaler for the treatment of COPD. Chest. 2003;124(3): 834-843.

15. Tashkin DP, Rennard SI, Martin P, et al. Efficacy and safety of budesonide and formoterol in one pressurized metered-dose inhaler in patients with moderate to very severe chronic obstructive pulmonary disease: results of a 6-month randomized clinical trial. Drugs. 2008;68(14):1975-2000.

16. Rennard SI, Tashkin DP, McElhattan J, et al. Efficacy and tolerability of budesonide/formoterol in one hydrofluoroalkane pressurized metered-dose inhaler in patients with chronic obstructive pulmonary disease: results from a 1-year randomized controlled clinical trial. Drugs. 2009;69(5):549-565.

17. Donohue JF, Kalberg C, Emmett A, Merchant K, Knobil K. A shortterm comparison of fluticasone propionate/salmeterol with ipratropium bromide/albuterol for the treatment of COPD. Treat Respir Med. 2004; 3(3):173-181

18. Jones PW, Agustí A, Chanez P, et al. A Phase III study evaluating aclidinium bromide, a novel long-acting antimuscarinic, in patients with COPD: ACCLAIM/COPD I [abstract]. Am J Respir Crit Care Med. 2009;179:A6180.

19. Rennard SI, Donohue JF, Bateman ED, Gross NJ, Garcia Gil E, Caracta C. Efficacy and safety of the novel, long-acting antimuscarinic, aclidinium bromide, in COPD patients in a Phase III study: ACCLAIM/ COPD II [abstract]. Am J Respir Crit Care Med. 2009;179:A6178.

20. Calverley PM, Anderson JA, Celli B, et al. Salmeterol and fluticasone propionate and survival in chronic obstructive pulmonary disease. N Engl J Med. 2007;356(8):775-789.

21. Stockley RA, Chopra N, Rice L. Addition of salmeterol to existing treatment in patients with COPD: a 12 month study. Thorax. 2006;61(2): $122-128$.

22. Campbell M, Eliraz A, Johansson G, et al. Formoterol for maintenance and as-needed treatment of chronic obstructive pulmonary disease. Respir Med. 2005;99(12):1511-1520.

23. Vogelmeier C, Kardos P, Harari S, Gans SJ, Stenglein S, Thirlwell J. Formoterol mono- and combination therapy with tiotropium in patients with COPD: a 6-month study. Respir Med. 2008;102(11):1511-1520. 
24. Celli BR, MacNee W. Standards for the diagnosis and treatment of patients with COPD: a summary of the ATS/ERS position paper. Eur Respir J. 2004;23(6):932-946.

25. American Thoracic Society. Standards for the diagnosis and care of patients with chronic obstructive pulmonary disease (COPD) and asthma. Am Rev Respir Dis. 1995;152:S77-S120.

26. Pauwels RA, Buist AS, Calverley PM, Jenkins CR, Hurd SS. Global strategy for the diagnosis, management, and prevention of chronic obstructive pulmonary disease. NHLBI/WHO Global Initiative for Chronic Obstructive Lung Disease (GOLD) workshop summary. Am J Respir Crit Care Med. 2001;163(5):1256-1276.

27. Miller MR, Hankinson J, Brusasco V, et al. Standardisation of spirometry. Eur Respir J. 2005;26(2):319-338.

28. Standardization of spirometry, 1994 update. American Thoracic Society. Am J Respir Crit Care Med. 1995;152(3):1107-1136.

29. Standardization of spirometry, 1987 update. Statement of the American Thoracic Society. Am Rev Respir Dis. 1987;136(5):1285-1298.

30. Beeh KM, Beier J, Buhl R, Stark-Lorenzen P, Gerken F, Metzdorf N. Efficacy of tiotropium bromide (Spiriva) in patients with chronicobstructive pulmonary disease (COPD) of different severities. Pneumologie. 2006;60(6):341-346.

31. Ferguson GT, Anzueto A, Fei R, Emmett A, Knobil K, Kalberg C. Effect of fluticasone propionate/salmeterol (250/50 microg) or salmeterol (50 microg) on COPD exacerbations. Respir Med. 2008;102(8): 1099-1108.

32. Decramer M, Celli B, Kesten S, Lystig T, Mehra S, Tashkin DP. Effect of tiotropium on outcomes in patients with moderate chronic obstructive pulmonary disease (UPLIFT): a prespecified subgroup analysis of a randomised controlled trial. Lancet. 2009;374(9696): 1171-1178.

33. Jenkins CR, Jones PW, Calverley PM, et al. Efficacy of salmeterol/ fluticasone propionate by GOLD stage of chronic obstructive pulmonary disease: analysis from the randomised, placebo-controlled TORCH study. Respir Res. 2009;10:59.

34. Calverley PM, Pauwels RA, Jones PW, Anderson JA, Vestbo J. The severity of airways obstruction as a determinant of treatment response in COPD. Int J Chron Obstruct Pulmon Dis. 2006;1(3): 209-218.

35. Anthonisen NR, Connett JE, Kiley JP, et al. Effects of smoking intervention and the use of an inhaled anticholinergic bronchodilator on the rate of decline of $\mathrm{FEV}_{1}$. The Lung Health Study. JAMA. 1994;272(19): 1497-1505.

36. Celli BR, Thomas NE, Anderson JA, et al. Effect of pharmacotherapy on rate of decline of lung function in chronic obstructive pulmonary disease: results from the TORCH study. Am J Respir Crit Care Med. 2008;178(4):332-338.

37. Vestbo J, Soriano JB, Anderson JA, Calverley PM, Pauwels R, Jones P. Gender does not influence the response to the combination of salmeterol and fluticasone propionate in COPD. Respir Med. 2004;98(11) 1045-1050.

38. Kohansal R, Martinez-Camblor P, Agustí A, Buist AS, Mannino DM, Soriano JB. The natural history of chronic airflow obstruction revisited: an analysis of the Framingham offspring cohort. Am J Respir Crit Care Med. 2009;180(1):3-10.

39. Mann M, Chowdhury B, Sullivan E, Nicklas R, Anthracite R, Meyer RJ. Serious asthma exacerbations in asthmatics treated with high-dose formoterol. Chest. 2003;124(1):70-74.

International Journal of COPD

\section{Publish your work in this journal}

The International Journal of COPD is an international, peer-reviewed journal of therapeutics and pharmacology focusing on concise rapid reporting of clinical studies and reviews in COPD. Special focus is given to the pathophysiological processes underlying the disease, intervention programs, patient focused education, and self management
40. Baumgartner RA, Hanania NA, Calhoun WJ, Sahn SA, Sciarappa K, Hanrahan JP. Nebulized arformoterol in patients with COPD: a 12-week, multicenter, randomized, double-blind, double-dummy, placebo- and active-controlled trial. Clin Ther. 2007;29(2):261-278.

41. Hanrahan JP, Hanania NA, Calhoun WJ, Sahn SA, Sciarappa K, Baumgartner RA. Effect of nebulized arformoterol on airway function in COPD: results from two randomized trials. COPD. 2008;5(1):25-34.

42. Suissa S. Lung function decline in COPD trials: bias from regression to the mean. Eur Respir J. 2008;32(4):829-831.

43. Keene ON, Celli B, Anderson JA, et al. Lung function decline in COPD trials. Eur Respir J. 2009;33(3):708-709; author reply 709-710.

44. Keene ON, Vestbo J, Anderson JA, et al. Methods for therapeutic trials in COPD: lessons from the TORCH trial. Eur Respir J. 2009;34(5): 1018-1023.

45. Troosters T, Celli B, Lystig T, et al. Tiotropium as a first maintenance drug in COPD: secondary analysis of the UPLIFT trial. Eur Respir J. 2010;36(1):65-73.

46. Welte T, Miravitlles M, Hernandez P, et al. Efficacy and tolerability of budesonide/formoterol added to tiotropium in patients with chronic obstructive pulmonary disease. Am J Respir Crit Care Med. 2009; 180(8):741-750.

47. Fabbri L, Pauwels RA, Hurd SS. Global strategy for the diagnosis, management, and prevention of chronic obstructive pulmonary disease: GOLD executive summary updated 2003. COPD. 2004;1(1):105-141.

48. Quanjer PH, Tammeling GJ, Cotes JE, Pedersen OF, Peslin R, Yernault JC. Lung volumes and forced ventilatory flows. Report Working Party Standardization of Lung Function Tests, European Community for Steel and Coal. Official Statement of the European Respiratory Society. Eur Respir J Suppl. 1993;16:5-40.

49. Calverley PM, Rennard SI. What have we learned from large drug treatment trials in COPD? Lancet. 2007;370(9589):774-785.

50. Kesten S, Rebuck AS. Is the short-term response to inhaled betaadrenergic agonist sensitive or specific for distinguishing between asthma and COPD? Chest. 1994;105(4):1042-1045.

51. Celli BR. Update on the management of COPD. Chest. 2008;133(6): 1451-1462.

52. Bleecker ER, Emmett A, Crater G, Knobil K, Kalberg C. Lung function and symptom improvement with fluticasone propionate/salmeterol and ipratropium bromide/albuterol in COPD: response by beta-agonist reversibility. Pulm Pharmacol Ther. 2008;21(4):682-688.

53. Calverley PM, Boonsawat W, Cseke Z, Zhong N, Peterson S, Olsson H. Maintenance therapy with budesonide and formoterol in chronic obstructive pulmonary disease. Eur Respir J. 2003;22(6):912-919.

54. Szafranski W, Cukier A, Ramirez A, et al. Efficacy and safety of budesonide/formoterol in the management of chronic obstructive pulmonary disease. Eur Respir J. 2003;21(1):74-81.

55. Burge PS, Calverley PM, Jones PW, Spencer S, Anderson JA, Maslen TK. Randomised, double blind, placebo controlled study of fluticasone propionate in patients with moderate to severe chronic obstructive pulmonary disease: the ISOLDE trial. BMJ. 2000;320(7245): 1297-1303.

56. Eichenhorn MS, Wise RA, Madhok TC, et al. Lack of long-term adverse adrenal effects from inhaled triamcinolone: Lung Health Study II. Chest. 2003;124(1):57-62.

57. Watson L, Vonk JM, Löfdahl CG, et al. Predictors of lung function and its decline in mild to moderate COPD in association with gender: results from the Euroscop study. Respir Med. 2006;100(4):746-753.

\section{Dovepress}

protocols. This journal is indexed on PubMed Central, MedLine and CAS. The manuscript management system is completely online and includes a very quick and fair peer-review system, which is all easy to use. Visit http://www.dovepress.com/testimonials.php to read real quotes from published authors. 